\title{
Alcohol intoxication and mental health among adolescents - a population review of 8983 young people, I3-19 years in North-Trøndelag, Norway: the Young-HUNT Study
}

\author{
Arve Strandheim*1,2,3, Turid Lingaas Holmen ${ }^{1,2}$, Lindsey Coombes ${ }^{4}$ and \\ Niels Bentzen ${ }^{1}$
}

\begin{abstract}
Address: ${ }^{1}$ Norwegian University of Science and Technology, the Faculty of Medicine, Department of Public Health and General Practice, Trondheim, Norway, ${ }^{2}$ Norwegian University of Science and Technology, the Faculty of Medicine, Department of Public Health and General University, the School of Health and Social Care, Oxford, UK

Email: Arve Strandheim* - arve.strandheim@ntnu.no; Turid Lingaas Holmen - turid.lingaas.holmen@ntnu.no; Lindsey Coombes - elcoombes@brookes.ac.uk; Niels Bentzen - niels.bentzen@ntnu.no

* Corresponding author
\end{abstract} Practice, HUNT research centre, Verdal, Norway, ${ }^{3}$ Nord-Trøndelag Health Trust, Sykehuset Levanger, Levanger, Norway and ${ }^{4}$ Oxford Brookes

Published: 23 June 2009

Child and Adolescent Psychiatry and Mental Health 2009, 3:18 doi:10.1 I86/1753-2000-3-18

This article is available from: http://www.capmh.com/content/3/1/18

(c) 2009 Strandheim et al; licensee BioMed Central Ltd.

This is an Open Access article distributed under the terms of the Creative Commons Attribution License (http://creativecommons.org/licenses/by/2.0), which permits unrestricted use, distribution, and reproduction in any medium, provided the original work is properly cited.
Received: 9 January 2009

Accepted: 23 June 2009

\begin{abstract}
Background: The aims of this study were to describe alcohol use among Norwegian teenagers and investigate the associations between mental health problems and alcohol intoxications with focus on age and gender.

Methods: Population based, cross-sectional survey addressing all adolescents aged 13-19 years, attending secondary or high school in North - Trøndelag County, Norway. 8983 youths (9l\%) answered the Young-HUNT questionnaire in the 1995-1997 survey. Logistic regression models were used to study associations.

Results: $80 \%$ of the respondents reported that they had tried drinking alcohol, and $57 \%$ had been intoxicated at least once. The proportion of the students, which had tried alcohol, was equal in both genders and increased with age. Attention problems and conduct problems were strongly associated with frequent alcohol intoxications in both genders. Anxiety and depressive symptoms among girls were also related to high numbers of intoxications
\end{abstract}

Conclusion: Gender differences in number of alcohol intoxications were small. There was a close association between both conduct and attention problems and high alcohol consumption in both genders. Girls with symptoms of anxiety and depression reported more frequent alcohol intoxications.

\section{Background}

In Europe earlier alcohol debut, higher alcohol consumption, and more polysubstance use among adolescents have been documented in the last decade [1-4]. Many studies, especially from the US emphases the health risks from early alcohol debut $[5,6]$. Alcohol intoxication has been described as a particular risk in adolescence, both from experiments and epidemiological research $[7,8]$. 
Adolescents in Europe, Australia and the US were attributed a pattern of binge drinking with frequent alcohol intoxication in several studies [2,7-9].

Associations of alcohol use in adolescence with several mental health problems, such as conduct problems, hyperactivity/attention problems, depression, anxiety and suicidal behaviour has been reported in several studies [2,10-14]. Childhood hyperactivity and attention deficit is considered a risk factor for later alcohol- and substance misuse $[15,16]$, although some researchers explain this as mediated by deviant peer affiliation [17]. On the other hand problem behaviours as conduct problems, alcohol and drug use have been considered a common syndrome in several studies $[18,19]$.

Age and gender specific population studies are rare, even though important differences are indicated in several articles [20-22]. Mood and anxiety disorders are overrepresented among women, while hyperactivity-, conduct- and substance use disorders are overrepresented among men, at least in clinical samples $[23,24]$. Existing population based research also indicates important gender- and age differences in the prevalence of common adolescent mental health problems [24-26], with possible influence on the association with alcohol use. Incidence rates indicates early onset (age 18-24) of alcohol and substance use disorders [25], with the closest relationship between alcohol use and mental health problems among the youngest adolescents [27]. Few European and especially Scandinavian population data are describing adolescents' alcohol use and relation to mental health [12]. The need for further studies has been identified in recent papers $[28,29]$ who pointed out that research in this area often have used small clinical samples. The Young-HUNT data set includes mental health problems in the total population of a region, which enables association studies with alcohol use and lifestyle data.

Thus the aims of this study were to examine the relationships between alcohol intoxications and common mental health problems in a total adolescence population, and focus on possible gender and age differences.

\section{Methods}

\section{Study population and design}

The county of Nord-Trøndelag, situated in the central Norway, has about 127.000 inhabitants. The Nord-Trøndelag Health Study (HUNT), conducted in 1995/97, invited all inhabitants 13 years and older to the survey. Students in secondary school and high school, 13-19 years, participated in the youth part of the study; YoungHUNT1http://www.hunt.ntnu.no, used in this work. Norway has a public school system for all students regardless of handicap or learning difficulties, special schools are rare. Secondary school is compulsory, while students have the right to attend a free high school education. Of a total of 10202 adolescents only 285 were not attending school. The design is cross-sectional, exploring associations of mental health problems and alcohol use in adolescence 13 - 19 years of age. The total population was divided in gender and age groups.

\section{Measures}

The students completed a comprehensive self-administered questionnaire in an exam setting during a school hour. Questions on physical and mental health, life style and socio-demographic factors were included.

To define problem groups from different scales, scores above the 70th percentile was used systematically in accordance to previous studies of anxiety and depression [30].

\section{Variables}

\section{Alcohol use}

Self reported numbers of lifetime alcohol intoxication episodes was the primary outcome measure. More than 10 intoxications were defined as high alcohol use in all age groups. The same definition has been used in previous studies and is known to be easy to collect, fairly stable and easily remembered by the youth [31]. In the descriptive part of the analysis, number of alcohol intoxications were divided in three; "no reported intoxication", "one to 10 intoxications" or "more than 10 intoxications". This gave substantial counts in all age and gender groups, and was supposed to discriminate different levels of alcohol involvement and risk. For the binary logistic regression analysis, the data regarding intoxication episodes were dichotomized into one group with 0-10 intoxication episodes, the other group with more than 10 intoxications [31].

To gain other measures of alcohol use the students also were asked to report the amount of beer, wine or spirit they usually drank during a 2-week period. The data were recalculated to grams of alcohol and then to alcohol units ( $8 \mathrm{~g}$ pr unit) [32]. The students drinking above the 70th percentile for this population, 3 or more units in 14 days, was defined high volume drinkers in the age group 13-19 years [33].

\section{Mental health}

The mental health variables were derived from the mental health "Symptom Check List" and the school adjustmentpart of the questionnaire.

\section{Anxiety and depression}

Symptoms of anxiety and depression were measured by SCL-5 (Symptom Check List), a five-item scale based on SCL-25, proven reliable in previous studies [30,34]. A factor analysis gave only one factor with Eigenvalue $>1$, mak- 
ing distinction between anxiety and depressive symptoms impossible. According to this analysis all five items were included in the anxiety/depressive variable (Anxiety problems: "been constantly scared and uneasy", "felt tense and restless" and "worries too much about different matters". Depressive problems: "felt hopeless when thinking of future" and "felt down or sad"). All questions had four alternative responses ranging from one: "not at all" to four: "extremely". The aggregated score of the SCL-5 questions were summarized and ranged from five to 20 . These scores constitute no true interval scale and was recalculated into dichotomous categorical variables with more than 8 points as the cut off point, according to former studies $[30,34]$.

\section{Attention and conduct problems}

The school adjustment part of the questionnaire with totally 14 items used to define behavioral problems, has been described previously [35]. A factor analysis using Varimax rotation with Kaiser Normalization defined 2 independent factors: attention- and conduct problems, both with an Eigenvalue $>1$. Attention problems include the items how often "do you have trouble concentrating in class" and "don't manage to be calm in class". Conduct problems include how often do you "quarrels with the teacher", "get into fights" and "get scolded by the teacher". All items had four alternative responses from one: "never" to four: "very often". Each category was recalculated into aggregated scores. Attention problems had a distribution from two to 8 , with median at four. Conduct problems ranked from tree to 12 . Both scales were dichotomised into "high" or "low" problem score, defining a high problem group over the $70^{\text {th }}$ percentile [30]. Scores of five or more constitutes the high problem groups concerning both attention and conduct problems.

\section{Analysis}

Descriptive statistic was derived from contingency tables with use of Pearson Chi-Square tests. In logistic regression models alcohol intoxication was used as dependent variable. Independent variables included were, anxiety/depres- sion, conduct problems and attention problems. Odds ratios (OR) and their corresponding 95\% confidence intervals (CI) were calculated from all analysis. Since alcohol consumption is known to increase with age and may differ between genders, interactions were calculated for each independent variable. Significant interaction was found for anxiety/depressive symptoms by gender ( $\mathrm{p}=$ 0.001 ), and nearly significant for anxiety/depressive symptoms by age $(\mathrm{p}=0.079)$. These interactions are both statistical and clinical meaningful, consequently all models were stratified by gender and the two age groups 13 5 and $16-19$ years.

\section{Ethical considerations}

Each student signed a written consent form. For the students younger than 16 the parent also gave their written consent. Anonymous results were communicated to local health authorities, to be used for planning of health services, in accordance with the consent given. The study was evaluated and approved by the Regional Medicine Ethics Committee and the Norwegian Data Inspectorate Board.

\section{Results}

Frequencies of alcohol use and mental health problems Among the 9917 students invited in the target grades, $91 \%$ (totally 8984,4507 boys, 4424 girls) answered the questionnaire, 94.8 in secondary schools and 85.6 in high schools. Of all the youths who completed the questionnaire, $43.3 \%$ reported that they never had been intoxicated by alcohol, and $28.9 \%$ reported more than 10 episodes of intoxication. The number of intoxications increased with age both among boys and girls (table 1). Gender difference was not found among those without experience of intoxication. Only slightly more boys than girls reported more than 10 intoxications. The gender difference was more obvious in the high volume-drinking group, which included $28.9 \%$ of boys and $19.6 \%$ of girls.

Attention problems, anxiety and depressive symptoms increased with age, and were more common in girls com-

Table I: Number of alcohol intoxications and high volume drinking by gender and age in Nord-Trøndelag, Norway $1995-97$.

\begin{tabular}{|c|c|c|c|c|c|c|c|c|c|}
\hline & & \multicolumn{4}{|c|}{ Boys } & \multicolumn{4}{|c|}{ Girls } \\
\hline & & \multicolumn{2}{|c|}{ Age $13-15$} & \multicolumn{2}{|c|}{ Age $16-19$} & \multicolumn{2}{|c|}{ Age $13-15$} & \multicolumn{2}{|c|}{ Age 16-19 } \\
\hline & & $N$ & $\%$ & $\mathrm{~N}$ & $\%$ & $\mathrm{~N}$ & $\%$ & $\mathrm{~N}$ & $\%$ \\
\hline \multirow[t]{3}{*}{ Intoxication } & 0 & 1575 & 68.2 & 400 & 18.2 & 1547 & 66.5 & 352 & 16.6 \\
\hline & $1-10$ & 584 & 25.3 & 563 & 25.6 & 640 & 27.5 & 699 & 33.0 \\
\hline & $>10$ & 149 & 6.5 & 1242 & 56.2 & 138 & 5.9 & 1066 & 50.4 \\
\hline \multirow[t]{2}{*}{ Alcohol volume* } & low & 2045 & 88.9 & 1143 & 52.4 & 2151 & 92.8 & 1405 & 66.7 \\
\hline & High & 256 & 11.1 & 1039 & 47.6 & 168 & 7.2 & 700 & 33.3 \\
\hline
\end{tabular}

* Low is defined as less than 3 alcohol units pr 14 days, high as 3 or more units. 
pared to boys; while high conduct problems decreased with age and were more common in boys (table 2).

\section{Associations of alcohol intoxication and mental health}

Attention problems, conduct problems, anxiety and depressive symptoms were highly associated with the number of alcohol intoxications the students had experienced. In the total population $25.1-26.8 \%$ of the student in the low problem groups had experienced more than 10 intoxications; while the corresponding prevalences in the high symptom score groups were $35.5-42.6 \% 8$ ( $\mathrm{p}=$ 0.001 for all) (table 3).

According to the interactions shown, the material was stratified in groups, with respect to gender and age (13$15,16-19)$. Stratified analysis showed that conduct problems were the most important association with boys' intoxications, followed by attention problems (table 4). The importance of both conduct (OR 3.5 versus 2.1) and attention problems (OR 3.0 versus 1.7 ) on the number of intoxications diminished with age. Among girls, the association of attention- and conduct problems with alcohol intoxications were equally strong, both diminishing with age. The changes by age of attention problems among boys seemed robust with separated Confidence Intervals, while the age changes among the other factor were questionable due to overlapping confidence intervals. Combined anxiety and depressive symptoms was associated with higher intoxication frequency only in girls.

\section{Discussion}

\section{Summary of main findings}

Alcohol use is prevalent among students aged $13-19$ years in North-Trøndelag, Norway, both measured by volume and frequency of intoxications. The high numbers of alcohol intoxication compared to the relative low total amount of alcohol consumed, indicated a pattern of heavy episodic drinking among adolescence in NordTrøndelag. The gender difference in alcohol use was small, consistent with description of diminishing gender differences both from Europe, US and Australia in the last decade [1,36-38]. There was a close association of high alcohol consumption with conduct and attention problems in both genders. Among boys, conduct problems had the closest association to frequent intoxications, while girls with attention problems and conduct problems where equally exposed. The strong relationship between frequent alcohol intoxication and symptoms of attention and conduct problems, has also been described in clinical research [39-41]. Few epidemiological studies deal with the relationship of individual mental health factors and possibly dangerous alcohol consumption $[27,39]$. In the Young HUNT data depressive- and anxiety symptoms were associated with high number of intoxications in girls, but not in boys. Some previous works find interaction with gender, and important gender differences [20], while others do not [27]. The divergence in findings may be due to methodological differences or local variation.

A substantial amount of literature is focused on the effect of early alcohol debut on mental health [42-46]. This study emphases the co-occurrence of mental health problems and intoxicant alcohol behaviour, consistent with recent clinical reports [47-49].

\section{Limitations and strengths}

The current data set is cross-sectional, and not suitable to determine causal relations. However, the Young-HUNT is a total cohort study, with a high response rate, and many methodological problems concerning samples could be excluded. $91 \%$ of the student participated; most of the nonparticipants were absent from school for health reasons, some did not consent and very few forms were not readable. The response rate from the adolescents not in school or in vocational training was low, and were excluded from the study. Even if they were few they would be an interesting group to include, and could possibly contribute to the associations measured.

The data is collected from adolescence 13-19 years old in the phase were both alcohol habits and mental health profile emerges. The questionnaire was designed with some pre-validated variables like SCL-5, while the questions of school behaviour have few earlier evaluations. These questions are similar to core diagnostic questions in DSM IV, but neither the questions in the school part of Young-HUNT, nor the SCL-5 questions have diagnostic

Table 2: Mental health problems by gender and age in adolescents, Nord-Trøndelag, Norway 1995-97

\begin{tabular}{|c|c|c|c|c|c|c|c|c|}
\hline & \multicolumn{4}{|c|}{ Boys } & \multicolumn{4}{|c|}{ Girls } \\
\hline & \multicolumn{2}{|c|}{ Age $13-15$} & \multicolumn{2}{|c|}{ Age $16-19$} & \multicolumn{2}{|c|}{ Age $13-15$} & \multicolumn{2}{|c|}{ Age $16-19$} \\
\hline & $\mathrm{N}$ & $\%$ & $N$ & $\%$ & $\mathrm{~N}$ & $\%$ & $\mathrm{~N}$ & $\%$ \\
\hline High attention problems score & 499 & 22.7 & 580 & 27.1 & 551 & 24.5 & 614 & 29.6 \\
\hline High conduct problems score & 964 & 43.7 & 744 & 34.9 & 673 & 29.9 & 461 & 22.2 \\
\hline High combined anxiety/depressive symptoms score* & 295 & 13.3 & 400 & 18.9 & 566 & 25.2 & 769 & 37.6 \\
\hline
\end{tabular}

* Anxiety symptoms and depressive symptoms derived from SCL-5, presented as a common variable based on all the 5 questions in SCL-5. 
Table 3: Prevalence of alcohol intoxications by mental health problems among adolescents, Nord-Trøndelag, Norway $1995-97$

\begin{tabular}{|c|c|c|c|c|c|}
\hline & & & Not intoxicated & $\mathrm{I}-10$ intoxications & $>10$ intoxications \\
\hline \multirow[t]{4}{*}{ Attention problems } & Low & $\mathrm{N}$ & 3026 & 1783 & 1614 \\
\hline & & $\%$ & 47.1 & 27.8 & 25.1 \\
\hline & High & $\mathrm{N}$ & 618 & 673 & 955 \\
\hline & & $\%$ & 27.5 & 30.0 & 42.6 \\
\hline \multirow[t]{4}{*}{ Conduct problems } & Low & $N$ & 2684 & 1584 & $|56|$ \\
\hline & & $\%$ & 46.0 & 27.2 & 26.8 \\
\hline & High & $\mathrm{N}$ & 966 & 868 & 1008 \\
\hline & & $\%$ & 34.0 & 30.5 & 35.5 \\
\hline \multirow[t]{4}{*}{ Anxiety and depressive symptoms } & Low & $N$ & 3039 & 1814 & 1740 \\
\hline & & $\%$ & 46.1 & 27.5 & 26.4 \\
\hline & High & $\mathrm{N}$ & 624 & 623 & 783 \\
\hline & & $\%$ & 30.7 & 30.7 & 38.6 \\
\hline
\end{tabular}

$P=0.000 \mathrm{I}$ for the differences between high and low symptom groups on more than 10 intoxications estimated by Pearsons Chi-square/likelihood ratio

specificity, and can only be used as measures of problems in the clusters addressed. All information used in the study was self-reported, and can contain both over- and under-estimates. Some recent studies indicated that selfreport on alcohol are reasonably reliable for adolescents $[31,50]$.

\section{Clinical and scientific implications}

The Young-HUNT study may suggest that adolescents with attention- and conduct problems are at high risk for alcohol problems. This is in accordance with recent research on attention and hyperactivity disorders

Table 4: Odds Ratio of $>10$ alcohol intoxications with high score of mental health problems. Binary logistic regression stratified by age and gender. Nord-Trøndelag, Norway 1995-97

\begin{tabular}{|c|c|c|c|c|c|}
\hline & & & OR & $95 \% \mathrm{Cl}$ & $\mathrm{P}$-value \\
\hline \multirow[t]{8}{*}{ Boys } & $13-15$ & & & & \\
\hline & & High attention problems & 3.0 & $2.1-4.4$ & 0.0001 \\
\hline & & High conduct problems & 3.5 & $2.3-5.3$ & 0.0001 \\
\hline & & High anxiety/depr. symp. & 0.9 & $0.5-1.5$ & 0.617 \\
\hline & $16-19$ & & & & \\
\hline & & High attention problems & 1.7 & $1.3-2.1$ & 0.0001 \\
\hline & & High conduct problems & 2.1 & $1.7-2.6$ & 0.0001 \\
\hline & & High anxiety/depr. symp. & 1.0 & $0.8-1.2$ & 0.8 \\
\hline \multicolumn{6}{|l|}{ Girls } \\
\hline & $13-15$ & & & & \\
\hline & & High attention problems & 2.7 & $1.8-4.0$ & 0.0001 \\
\hline & & High conduct problems & 2.4 & $1.6-3.6$ & 0.0001 \\
\hline & & High anxiety/depr. symp. & 1.7 & $1.1-2.5$ & 0.015 \\
\hline & $16-19$ & & & & \\
\hline & & High attention problems & 2.1 & $1.7-2.0$ & 0.0001 \\
\hline & & High conduct problems & 1.9 & $1.5-2.4$ & 0.0001 \\
\hline & & High anxiety/depr. symp. & 1.4 & $1.1-1.7$ & 0.001 \\
\hline
\end{tabular}

described as precursor of alcohol and other drug misuse $[17,51-54]$. Conduct problems, however, is known to be related to adolescents' alcohol use, and the problems tends to develop further in young adulthood $[18,55]$. Alcohol intoxication in adolescence may indicate an independent risk for later mental health problems [56]. In accordance with the present findings and substantial international research, adolescents with attention- and conduct problems and their families, should be offered information and health advice adjusted to their situation. The possibility of a complicating alcohol habit to their previous behavioural problems is probable. Caretakers and doctors that handle girls with anxiety and depressive symptoms should bear in mind that this may increase the risk for alcohol problems developing in adolescence. All adolescents with conduct - and attention problems and girls with anxiety and depressive symptoms might be a very relevant target for indicated alcohol prevention interventions. On the other hand, the findings from this study do not oppose universal preventive strategies (i.e. age limits, sales restrictions); it might benefit the whole adolescence population, and give extra health promotion also for the groups at risk.

The co-occurrence of frequent alcohol intoxications and psychiatric problems in adolescence identified in this study may indicate common background traits or possible existence of causal relations between mental health and alcohol use.

This study supports the view that attention problems and conduct problems may play a part in the development of harmful alcohol use in adolescence. Another interpretation is that attention-, conduct- and substance use problems are different expression of the same traits in the adolescence population [57]. That alcohol intoxication or 
alcohol use should generate the mental heath problems described, seems less likely, especially conduct- and attention problem tend to emerge early in childhood. This cross-sectional material does not solve that problem, but further prospective studies and qualitative research might contribute.

\section{Conclusion}

Gender differences in number of alcohol intoxications among adolescence 13-19 years old in Nord-Trøndelag, Norway were small. The number of intoxications increased with age both among boys and girls. There was a close association between both conduct and attention problems and frequent alcohol intoxications in both genders. Girls with high scores of depressive and anxiety symptoms reported more frequent alcohol intoxications compared to girls with few symptoms. The associations described were strongest in the youngest groups (13-16). Both clinical practice and prevention may emphasis more on the alcohol habits of young adolescents with attentionand conduct problems, and girls with anxiety or depressive symptoms. Further prospective or qualitative studies may contribute to the understanding of alcohol- and mental health problems developing in adolescence.

\section{Competing interests}

The authors declare that they have no competing interests.

\section{Authors' contributions}

AS participated in designing the study, performed the analysis and drafted the article. TLH is the PI of the YoungHUNT-study and participated in the design, statistical analysis, drafting and presentation of the results. LC participated in the description of background, especially UK and European research, statistical analysis, drafting and presentation. NB was essential in the development of the idea, description and thinking of the study, as well as drafting of the article. All authors have read and approved of the final manuscript.

\section{Acknowledgements}

We would like to thank the Central Norway Regional Health Authority and the County Council of Nord-Trøndelag for funding and support. The Youth part of the HUNT study is collaboration between HUNT Research Centre, Faculty of medicine, The Norwegian University of Science and Technology (NTNU), Norwegian Institute of Public Health and Nord-Trøndelag County Council.

In particular we thank researcher Grethe Bratberg for use of her variables, help and advice.

\section{References}

I. Andersson B, Hansagi H, Damstrom TK, Hibell B: Long-term trends in drinking habits among Swedish teenagers: National School Surveys 197 I-1999. Drug Alcohol Rev 2002, 2 I:253-260.

2. Kuntsche E, Rehm J, Gmel G: Characteristics of binge drinkers in Europe. Soc Sci Med. 2004, 59(I): I I3-127.
3. McArdle P, Wiegersma A, Gilvarry E, Kolte B, McCarthy S, Fitzgerald M, Brinkley A, Blom M, Stoeckel I, Pierolini A, Michels I, Johnson R, Quensel S: European adolescent substance use: the roles of family structure, function and gender. Addiction 2002, 97:329-336

4. Michaud P, Berchtold A, Eannin A, Chossis I, Suris JC: Secular trends in legal and illegal substance use among 16-20-yearold adolescents in Switzerland. Swiss Medical Weekly 2006, I36:318-326.

5. Grant BF, Stinson FS, Harford TC: Age at onset of alcohol use and DSM-IV alcohol abuse and dependence: A I2-year follow-up. J Subst Abuse 200I, I 3:493-504.

6. Hingson R, Heeren T, Levenson S, Jamanka A, Voas R: Age of drinking onset, driving after drinking, and involvement in alcohol related motor-vehicle crashes. Accid Anal Prev 2002, 34:85-92.

7. Barron S, White A, Swartzwelder HS, Bell RL, Rodd ZA, Slawecki CJ, Ehlers CL, Levin ED, Rezvani AH, Spear LP: Adolescent vulnerabilities to chronic alcohol or nicotine exposure: findings from rodent models. Alcohol Clin Exp Res 2005, 29: I720-I725.

8. Monti PM, Miranda R, Nixon K, Sher KJ, Swartzwelder HS, Tapert SF, White A, Crews FT: Adolescence: Booze, brains, and behavior. Alcoholism-Clinical and Experimental Research 2005, 29:207-220.

9. Reboussin BA, Song EY, Shrestha A, Lohman KK, Wolfson M: A latent class analysis of underage problem drinking: Evidence from a community sample of 16-20 year olds. Drug Alcohol Depend 2006, 83:199-209.

10. Collishaw S, Maughan B, Goodman R, Pickles A: Time trends in adolescent mental health. J Child Psychol Psychiatry. 2004, 45(8): | 350- | 362.

II. Lynch F, Mills C, Daly I, Fitzpatrick C: Challenging times: prevalence of psychiatric disorders and suicidal behaviours in Irish adolescents. J Adolesc 2006, 29:555-573.

12. Rossow I, Groholt B, Wichstrom L: Intoxicants and suicidal behaviour among adolescents: changes in levels and associations from 1992 to 2002. Addiction 2005, 1 00:79-88.

13. Simpson K, Janssen I, Boyce WF, Pickett W: Risk taking and recurrent health symptoms in Canadian adolescents. Prev Med 2006, 43:46-5I.

14. Tarter RE, Kirisci L, Feske U, Vanyukov M: Modeling the pathways linking childhood hyperactivity and substance use disorder in young adulthood. Psychology of Addictive Behaviors 2007, 2I:266-27I.

I5. Elkins IJ, McGue M, lacono WG: Prospective effects of attentiondeficit/hyperactivity disorder, conduct disorder, and sex on adolescent substance use and abuse. Arch Gen Psychiatry 2007, 64: I I45-I I 52.

16. Niemela S, Sourander A, Poikolainen K, Helenius H, Sillanmaki L, Parkkola K, Piha J, Kumpulainen K, Almqvist F, Moilanen I: Childhood predictors of drunkenness in late adolescence among males: a I0-year population-based follow-up study. Addiction 2006, I 0 I:512-52I

17. Marshal MP, Molina BSG, Pelham WE: Childhood ADHD and adolescent substance use: An examination of deviant peer group affiliation as a risk factor. Psychology of Addictive Behaviors 2003, I 7:293-302.

18. Begg DJ, Gulliver P: A longitudinal examination of the relationship between adolescent problem behaviors and traffic crash involvement during young adulthood. Traffic Inj Prev 2008, 9:508-5।4.

19. Donovan JE, Jessor R: Structure of problem behavior in adolescence and young adulthood. J Consult Clin Psychol 1985, 53:890-904.

20. Laukkanen ER, Shemeikka SL, Viinamaki HT, Polkki PL, Lehtonen JO: Heavy drinking is associated with more severe psychosocial dysfunction among girls than boys in Finland. J Adolesc Health 200I, 28:270-277.

21. McArdle P, Wiegersma A, Gilvarry E, McCarthy S, Fitzgerald M, Kolte B, Brinkley A, Blom M, Stoeckel I, Pierolini A, Michels I, Johnson R, Quensel S: International variations in youth drug use: the effect of individual behaviours, peer and family influences, and geographical location. Eur Addict Res 2000, 6:163-169.

22. McGue M, lacono WG: The association of early adolescent problem behavior with adult psychopathology. Am J Psychiatry 2005, 162: III8-II24.

23. Biederman J, Kwon A, Aleardi M, Chouinard VA, Marino T, Cole H, Mick E, Faraone SV: Absence of gender effects on attention def- 
icit hyperactivity disorder: Findings in nonreferred subjects. Am J Psychiatry 2005, 162:1083-1089.

24. Ribeiro SN, Jennen-Steinmetz C, Schmidt MH, Becker K: Nicotine and alcohol use in adolescent psychiatric inpatients: associations with diagnoses, psychosocial factors, gender and age. Nord J Psychiatry 2008, 62:315-321.

25. Bijl RV, DE GR, Ravelli A, Smit F, Vollebergh WA: Gender and agespecific first incidence of DSM-III-R psychiatric disorders in the general population. Results from the Netherlands Mental Health Survey and Incidence Study (NEMESIS). Soc Psychiatry Psychiatr Epidemiol 2002, 37:372-379.

26. Turner RJ, Gil AG: Psychiatric and substance use disorders in South Florida: racial/ethnic and gender contrasts in a young adult cohort. Arch Gen Psychiatry 2002, 59:43-50.

27. Verdurmen J, Monshouwer K, van Doorsselaer S, ter Bogt T, Vollebergh W: Alcohol use and mental health in adolescents: interactions with age and gender-findings from the Dutch $200 \mathrm{I}$ Health Behaviour in School-Aged Children survey. I Stud Alcohol 2005, 66:605-609.

28. Dani JA, Harris RA: Nicotine addiction and comorbidity with alcohol abuse and mental illness. Nat Neurosci 2005 8: $1465-1470$

29. Kreek MJ, Nielsen DA, Butelman ER, Laforge KS: Genetic influences on impulsivity, risk taking, stress responsivity and vulnerability to drug abuse and addiction. Nat Neurosci 2005 , 8: | $450-1457$.

30. Tambs K, Moum T: How well can a few questionnaire items indicate anxiety and depression? Acta Psychiatr Scand 1993, 87:364-367.

3I. Lintonen T, Ahlstrom S, Metso L: The reliability of self-reported drinking in adolescence. Alcohol Alcohol 2004, 39:362-368.

32. Dawson DA: Measuring alcohol consumption: limitations and prospects for improvement. Addiction 1998, 93:965-968.

33. Bratberg GH, Nilsen TI, Holmen TL, Vatten LI: Sexual maturation in early adolescence and alcohol drinking and cigarette smoking in late adolescence: a prospective study of 2,129 Norwegian girls and boys. Eur J Pediatr 2005, 164:62I-625.

34. Strand BH, Dalgard OS, Tambs K, Rognerud M: Measuring the mental health status of the Norwegian population: a com parison of the instruments SCL-25, SCL-10, SCL-5 and MHI5 (SF-36). Nord J Psychiatry 2003, 57: I I3-II8.

35. Storksen I, Roysamb E, Holmen TL, Tambs K: Adolescent adjustment and well-being: effects of parental divorce and distress. Scand J Psychol 2006, 47:75-84.

36. Bu ETH, Watten RG, Foxcroft DR, Ingebrigtsen JE, Relling G: Teenage alcohol and intoxication debut: The impact of family socialization factors, living area and participation in organized sports. Alcohol Alcohol 2002, 37:74-80.

37. Plant M, Miller P: Young people and alcohol: An international insight. Alcohol Alcohol 200I, 36:5 I3-5 I5.

38. Maxwell IC: Are we becoming more alike? Comparison of substance use in Australia and the United States as seen in the 1998, 200 I and 2004 national household surveys. Drug Alcohol Rev. 1995, 27(5):473-48।.

39. Molina BSG, Pelham WE: Childhood predictors of adolescent substance use in a longitudinal study of children with ADHD. J Abnorm Psychol 2003, I I 2:497-507.

40. Pirkola SP, Isometsa E, Suvisaari J, Aro H, Joukamaa M, Poikolainen K, Koskinen S, Aromaa A, Lonnqvist JK: DSM-IV mood-, anxietyand alcohol use disorders and their comorbidity in the Finnish general population - Results from the Health 2000 Study. Soc Psychiatry Psychiatr Epidemiol 2005, 40: I- 10.

41. Rohde P, Lewinsohn PM, Seeley JR: Psychiatric comorbidity with problematic alcohol use in high school students. I Am Acad Child Adolesc Psychiatry 1996, 35:101-109.

42. Miller P, Plant M: Truancy and perceived school performance: An alcohol and drug study of UK teenagers. Alcohol Alcohol 1999, 34:886-893.

43. Miller P, Plant M: Teenage alcoholic beverage preferences: risks and responses. Health Risk \& Society 2003, 5:3-9

44. Nemtsov A: Suicides and alcohol consumption in Russia, 1965-1 999. Drug Alcohol Depend 2003, 71:161-168.

45. Pedersen W, Skrondal A: Alcohol consumption debut: Predictors and consequences. J Stud Alcohol 1998, 59:32-42.
46. Rossow I, Wichstrom L: Parasuicide and Use of Intoxicants Among Norwegian Adolescents. Suicide Life Threat Behav 1994, 24:174-183.

47. Kaplow JB, Curran PJ, Angold A, Costello EJ: The prospective relation between dimensions of anxiety and the initiation of adolescent alcohol use. J Clin Child Psychol 200I, 30:316-326.

48. Kaplow JB, Curran PJ, Dodge KA: Child, parent, and peer predictors of early-onset substance use: A multisite longitudinal study. J Abnorm Child Psychol 2002, 30:199-216.

49. Khantzian EJ: The self-medication hypothesis of substance use disorders: A reconsideration and recent applications. Harv Rev Psychiatry 1997, 4:23|-244.

50. Clark DB, Chung T, Martin C: Alcohol use frequency as a screen for alcohol use disorders in adolescents. Int J Adolesc Med Health 2006, 18:181-187.

51. Biederman J, Monuteaux MC, Mick E, Spencer T, Wilens TE, Silva JM, Snyder LE, Faraone SV: Young adult outcome of attention deficit hyperactivity disorder: a controlled 10-year follow-up study. Psychol Med 2006, 36:167-179.

52. Lopez B, Schwartz SJ, Prado G, Huang S, Rothe EM, Wang W, Pantin $\mathrm{H}$ : Correlates of early alcohol and drug use in Hispanic adolescents: examining the role of ADHD with comorbid conduct disorder, family, school, and peers. I Clin Child Adolesc Psychol 2008, 37:820-832

53. Szobot CM, Rohde LA, Bukstein O, Molina BS, Martins C, Ruaro P, Pechansky F: Is attention-deficit/hyperactivity disorder associated with illicit substance use disorders in male adolescents? A community-based case-control study. Addiction 2007, 102:1122-1130.

54. Wilens TE, Biederman J: Alcohol, drugs, and attention-deficit/ hyperactivity disorder: a model for the study of addictions in youth. J Psychopharmacol 2006, 20:580-588.

55. Farrell AD, Danish SJ, Howard CW: Relationship between drug use and other problem behaviors in urban adolescents. J Consult Clin Psychol 1992, 60:705-7I2.

56. White AM, Swartzwelder HS: Age-related effects of alcohol on memory and memory-related brain function in adolescents and adults. Recent Dev Alcohol 2005, 17:161-176.

57. Jessor R: Problem-behavior theory, psychosocial development, and adolescent problem drinking. $\mathrm{Br} J$ Addict 1987, 82:331-342
Publish with Bio Med Central and every scientist can read your work free of charge

"BioMed Central will be the most significant development for disseminating the results of biomedical research in our lifetime. "

Sir Paul Nurse, Cancer Research UK

Your research papers will be:

- available free of charge to the entire biomedical community

- peer reviewed and published immediately upon acceptance

- cited in PubMed and archived on PubMed Central

- yours - you keep the copyright

Submit your manuscript here:

http://www.biomedcentral.com/info/publishing_adv.asp
BioMedcentral 